This document is the Accepted Manuscript version of a Published Work that appeared in final form in British Journal of Healthcare Management, copyright (C) MA Healthcare, after peer review and technical editing by the publisher. To access the final edited and published work see https://doi.org/10.12968/bjhc.2017.23.4.154

\title{
Brexit the consequences and impact on the health sector
}

\section{Bryan McIntosh, Reader in Health Management and Organisational Behaviour, University of Bradford}

\section{Sue West, Lecturer in Health Management \& Leadership, University of Bradford}

Even prior to the conclusion of the European Union (EU) referendum (Brexit), the NHS was showing tremendous signs of strain. Immediately after the outcome was announced, promises of major reinvestment of funds saved from payments to the EU were retracted. Since then, hospital closures, cuts and changes to health and social care have been revealed, with regular news broadcasts highlighting the crisis facing the NHS. The uncertainties about post-Brexit relationships, economy, politics and security are likely to further significantly impact the NHS and its sustainability. Higher Education Institutions (HEIs) and the NHS are inextricably linked through research and education of health and social care professionals - changes therefore having implications for both.

Workforce planning and investment in pre-registration education of health and social care professionals has been 'too little, too late' to take account of demographics such as the ageing workforce, increased population and complexities of conditions. Major public inquiries in recent years, such as the Francis (DoH, 2013) and Kirkup (2015) reports, have emphasised the importance of safe staffing levels, but recent publications have highlighted that these recommendations are already proving unfeasible. A compensatory increase in recruitment of staff from outside the UK has been seen in many areas. The EU has been increasingly targeted in view of the harmonisation of educational requirements and professional checks in the Mutual Recognition of Professional Qualifications Directive (NHS Employers, 2016a), which supplements existing legislation of freedom of movement for professional groups. The impact on this post Brexit is an unknown?

This is not the only issue facing the sector; retention of pre-registration health professional students as well as qualified staff is an ongoing issue. Staff shortages have served to further pressurise the existing workforce, resulting in increased sickness levels and attrition. The funding changes, particularly the decision to remove the bursary system for nurses, midwives and Allied health professionals from September 2017 is creating great uncertainty and the consequences on an already depleted workforce is not clear. The Government does not appear to appreciate that this decision will not markedly increase the workforce - student numbers for most health professions being limited by capacity in clinical areas or consider that the availability of student placements being a limiting factor. The future funding of clinical psychology training remains precariously unclear, despite the Government's acceptance of the recent final report of the Mental Health Taskforce which emphasises the importance of mental health issues (2016).

The economy and privatisation are long-term issues. Interest rates having been reduced in an effort to bolster the economic and reduce the sustained impact of austerity measures. The exchange rate has deteriorated and the implementation of Brexit is anticipated to further threaten markets. Resources available to health services, education and research are likely to reduce, negatively affecting quality of care provision to the public and the sustainability of the NHS. There is an 
increasing likelihood of private sector involvement to counteract this. This will be exacerbated by delays in regulatory changes. The uncertainties about changes to legislation regarding EU Directives may have an impact on the ability of the Nursing and Midwifery Council (NMC) to meet its current timeline for reviewing the standards for pre-registration nursing and midwifery education and mentorship; the same is likely to apply to other regulatory bodies. This will impede the ability of HEls to develop contemporary curricula which prepare professionals to be fit for purpose and practice.

Though the Government has introduced key strategic targets which promote joined-up working between, and within, health and social care (NHS England, 2014 and Willis, 2015), such interprofessional collaboration requires investment in both services and education. It will need to fund enhanced mental health services. These have already been identified by the Government as a key area of focus. Recent world events have suggested that political and social upheaval and incidents may, in part, be due to or exacerbate existing mental health issues and potentially cause new problems (Mclntosh \& McClelland, 2017). The media (in all its forms) plays a role in highlighting fearprovoking events. Social exclusion, economic difficulties and anxiety have major impact on mental health - and in turn on physical and social wellbeing; all of which have implications for staffing.

As stated above, registrants from Europe have typically held more equitable qualifications than some other countries due to EU Directives. Recruitment of healthcare registrants from this 'pool' is now under threat due to potential changes to free movement. This has implications for staffing, patient safety, quality of care and the sustainability of the NHS. Limitations to recruitment of high calibre health and social care academics from Europe will also have a detrimental effect on UK health education and research. No reassurance has yet been received that the status of existing EU employees will be protected, although Theresa May has recently stated that "We want to guarantee the rights of EU citizens who are already living in Britain, and the rights of British nationals in other member states, as early as we can" (May, 2017). Experienced staffs who are already employed in the UK may choose, or have, to return to their native countries - further depleting both clinical services and education. Current workforce planning will not have allowed for this, and any remedial modifications will take years to have an effect. The NHS will suffer in the meantime - potentially irrevocably. Private companies will be more likely to invest in skilled workers from other countries (permits allowing), increasing their ability to be providers of both healthcare and education.

Regarding education, despite the Government's promise to honour current arrangements for EU students until 17/18 (DoE, 2016), future restrictions to the 'four freedoms' will mean that international rates will need to be paid by all non-UK citizens - a much higher rate than the current 'home fees'. This will make the UK a less attractive place to undertake professional health and social care programmes, decreasing the applicant 'pool', diversity and ultimately NHS staffing even further. Furthermore, student and staff Erasmus exchanges, which currently enable significant collaboration on education development and initiatives, are in jeopardy.

This will not be the only consequence, Universities in the UK have, until now, been major beneficiaries of EU funding for research. This has enabled production of nursing, medicine, health and social care evidence of international significance. Collaborative agreements and bid applications for UK researchers relating to EU-funded projects have already reduced as a direct result of Brexit. Not only does this compromise the income for HEls, but it also reduces the scope of research 
available in the UK - with a direct impact on international reputation and high-quality outputs. Although the Autumn Statement revealed increased investment in research and development (Research Councils UK, 2016), allocation to health research has not been specified. May (2017) has recently indicated that the UK will continue to play "a leading role in science and innovation". It is to be hoped that Brexit negotiations will result in health receiving a strong focus, to mutual benefit of the UK and EU.

The current use of the NHS by non-UK citizens is likely to decrease if free movement is restricted, resulting in increased availability of its resources to the national population. Recent proposals for patient passport checks have, however, caused concern amongst professionals who do not see this as their role and are discomforted by what is perceived to be a discriminatory approach. The European Health Insurance Card (EHIC) currently ensures reciprocal arrangements for EU citizens, which is highly beneficial to UK expats and tourists. Any gains from not offering this facility to travellers to the UK are likely to be outweighed by the costs to its citizens abroad.

There are staffing implications if the UK healthcare and education workforce is depleted due to restrictions on free movement. The EU could experience positive outcomes in that it may reduce the 'brain drain' from these countries - both from currently qualified staff and potential recruits. Partnership arrangements are in place in several areas. The reduction to, or cessation of, this access could restrict opportunities for non-UK citizens to enhance their skills and professional development. This may have a negative impact on their expertise which could otherwise be transferred back to their home countries. Also restricting Health and social care research will result in reduced collaboration and investment in research which will have negative effects on the EU as well as the UK while the introduction of a levy on 'Tourist' healthcare will potentially result in a loss of reciprocal healthcare arrangements. This will directly affect expats and visitors in both the UK and EU - a negative for both groups

The Government needs to provide a guarantee of as much free movement of health and social care clinicians, educationalists and researchers as possible. This will promote continuity of the diversity and richness of skills, experience and innovations to be shared to mutual benefit, as well as reducing the impact on staffing numbers. It is crucial that those staff from EU and other countries who remain in the UK or enter the clinical or educational workforce feel valued and respected as a basic human right as well as promoting the quality of their practice. Explicit messages of inclusion from institutions, professional bodies, trade unions, government and the media need to continue and become even more high profile. Residential and employment status for existing staff from the EU needs to be protected. International university students should be excluded from net migration figures.

The Government should urgently review the decision to remove the bursary for healthcare students, as this was made prior to the outcome of the EU referendum being known. The consequences of Brexit are likely to lead to difficulties recruiting qualified nurses, midwives and allied health professionals from Europe to meet the demands of the NHS, even if 'Tier 2' visas are more readily available to this staffing group in any future immigration policy. Incentives are therefore needed to ensure ongoing recruitment and retention of UK students; some arrangement (as proposed by eminent figures in the health sector) to repay fees after a period of service within the NHS should be 
considered as a minimum. It needs to ensure that changes to existing EU legislation affecting health professional education are minimised to only those which will be of greater benefit to the UK than currently, informing the setting of educational standards by the NMC, GMC (General Medical Council) and HCPC (Health Care Professions Council).

The Government needs to invest in education of health professionals and social care workers for the long-term benefit of the population. Investment should not be restricted to pre-registration education; specialist knowledge and post graduate development are essential to promote expertise and innovation. Inter-professional learning is of great importance. Education providers need to consider alternative options to remain 'open for business' e.g.: extend online/ distance learning and invest in technology to support this. Consider increasing global partnerships and access to UK facilities for mutual benefit. This will help surmount barriers imposed as a result of reducing freedom of movement to live or work, should this be an outcome of negotiations.

Investment in health and social care research is essential - the UK leads in many areas and this needs to continue. Historical impact on the world has been major - we owe it to our fellow citizens to continue to contribute meaningfully to the promotion of health and wellbeing globally. Similarly, the UK has much to learn and benefit from international partners. Promotion of collaborative working between countries will enhance international relationships. This will have a positive benefit on the reputation of the country and its economy - and perhaps even contribute to world stability and security. Investment is required in mental health - building on existing Department of Health proposals and recognising the likely increase in mental health issues as a result of the current uncertainties, economic constraints and security fears nationally and internationally. The increased vulnerability of the disaffected, displaced, minority and marginal groups when developing policies needs to be recognised.

Finally, the Government should consider sustainability of staff and resources, seeking prevention rather than reaction. Investment in staff and their wellbeing, such as compassionate care initiatives, will have positive repercussions for patients/clients and the quality of care provided, resulting in long-term benefits, including economic savings. A positive outlook should be promoted as far as possible, while being realistic. Negativity breeds dissatisfaction, fear and anxiety with consequent physical/ mental and social ill-health. 'Good news' (such as recent Olympic successes) promotes patriotism and a sense of community. We as a society need to build, rather than destroy, individual aspirations and sense of value. Politicians and the media can play a major part in this. We need to ensure strong leadership at all levels, from Government to local educational and clinical providers engaging with, genuinely listening to and advocating for those involved. The newly formed 'Cavendish Coalition' is likely to be pivotal in this (NHS Employers, 2016b). Decision-making needs to be collaborative, with participation of service users and those who deliver education, health and social care and research. Clarity of communication and ownership of change is essential. 


\section{References}

Department for Education and Johnson, J. (2016) Funding support for EU students (Press release, 11 October 2016). GOV.UK. [Online], Available:

https://www.gov.uk/government/news/funding-support-for-eu-students [12.12.16]

Department of Health (2013) Report of the Mid Staffordshire NHS Foundation Trust Public Inquiry (Francis Report), Executive summary. London: The Stationery Office Limited. [Online], Available:

http://www.midstaffspublicinquiry.com/sites/default/files/report/Executive\%20summary.pdf [15.8.16]

Kirkup, B. (2015) The Report of the Morecambe Bay Investigation. London: The Stationery Office. [Online], Available:https://www.gov.uk/government/uploads/system/uploads/attachment_data/file/408480/ 47487_MBI_Accessible_v0.1.pdf [15.8.16]

May, T. (2017) Speech by Theresa May, Lancaster House (17 January 2017). [Online], Available: http://www.telegraph.co.uk/news/2017/01/17/theresa-mays-brexit-speech-full/ [21.1.17]

McIntosh, B \& McClelland, T (2017) "Mental Health Nursing: A new beginning or the end of the old order?", British Journal of Mental Health Nursing , 6 (1), 6-7

NHS Employers (2016a) Mobility of health professionals across Europe. NHS Employers. [Online], Available: http://www.nhsemployers.org/your-workforce/recruit/employerledrecruitment/international-recruitment/mobility-of-health-professionals-across-europe [15.8.16]

NHS Employers (2016b) The Cavendish Coalition.[Online], Available:

http://www.nhsemployers.org/your-workforce/need-to-know/brexit-and-the-nhs-euworkforce/thecavendish-coalition [8.9.16]

NHS England (2014) The NHS Five Year Forward View. London: The Stationery Office. [Online], Available: http://www.england.nhs.uk/wp-content/uploads/2014/10/5yfv-web.pdf [15.8.16]

Research Councils UK (2016) Research Councils welcome new funding in the Autumn Statement (Press release, 23 November 2016). Research Councils UK. [Online], Available: http://www.rcuk.ac.uk/media/news/161123/ [12.12.16]

The Mental Health Taskforce (2016) The Five Year Forward View for Mental Health. [Online], Available: https://www.england.nhs.uk/mentalhealth/2016/02/15/fyfv-mh/ [21.8.16] Willis, G.P. (2015) Raising the Bar. Shape of Caring: A Review of the Future Education and Training of Registered Nurses and Care Assistants. [Online], Available: London: Health Education England. Available: https://hee.nhs.uk/our 